\title{
Dosimetry study of East Kazakhstan residents by tooth enamel EPR spectroscopy
}

\author{
Kassym Zhumadilov ${ }^{1, *}$, Alexander Ivannikov ${ }^{2}$, Valeriy Skvortsov ${ }^{2}$, Valeriy Stepanenko ${ }^{2}$, \\ Tolebay Rakhypbekov ${ }^{3}$, and Masaharu $\mathrm{Hoshi}^{4}$ \\ ${ }^{1}$ L.N. Gumilyov Eurasian National University, Munaitpasova 13, Astana 010008, Kazakhstan \\ ${ }^{2}$ A.F. Tsyb Medical Radiological Research Center, 4, Korolev str., Obninsk, 249036, Russia \\ ${ }^{3}$ Semey State Medical University, Abaya Str., 103, Semey 071400, Kazakhstan \\ ${ }^{4}$ Hiroshima University, 734-8553, Japan
}

\begin{abstract}
The tooth enamel electron paramagnetic resonance (EPR) dosimetry method was used to determine accidental doses of population of settlements in the vicinity of the Semipalatinsk Nuclear Test Site (SNTS), Kazakhstan. The influence of four explosions to the populations was included into this report. The distances between investigated settlements and Ground Zero (SNTS) are in the range of 70-200 km from SNTS. Most of settlements (Dolon, Mostik, Bodene, Cheremushki, Kanonerka) are located near the central axis of radioactive fallout trace from the most contaminating surface nuclear test, which was conducted in 29, August 1949. The other settlements located close to radioactive fallout trace result in a surface nuclear tests in 24, August 1956 (Ust-Kamenogorsk, Znamenka, Shemonaikha, Glubokoe, Tavriya, Gagarino), in 12 august 1953 (Sarzhal) and in 7, August 1962 (Akzhar, Kurchatov, Begen, Semenovka, Buras, Grachi). Tooth samples were extracted according to medical recommendations in a course of ordinary dental treatment.
\end{abstract}

\section{Introduction}

In the period from 1949 to 1962125 nuclear tests (including 25 near-surface nuclear tests) were conducted at the Ground Zero technical site in the territory of Semipalatinsk Nuclear Test Site (SNTS). 11 of surface explosions heavily contaminated a huge territory of East Kazakhstan. Only the data of influence from four explosions to the population was included into this report [1-4].

The date of 29 August 1949 represents the first nuclear explosion, which contaminated a huge territory northeast from the epicenter by radioactive fallout (Dolon, Mostik, Bodene, Cheremushki, Kanonerka villages). The radioactive dust cloud was transferred by the wind and its gradual precipitation formed several radioactive fallout traces [5-8]. There is no data describing the dynamics of the precipitation of the dust from the radioactive cloud on the region adjacent to the SNTS. It is a very complicated procedure to reconstruct the individual and collective radiation doses obtained by the local population. This is

\footnotetext{
${ }^{*}$ Corresponding author: zhumadilovk@gmail.com
} 
a sophisticated procedure combining data of the radioactive fallout, individual doses measured by EPR, doses reconstructed from retrospective area dosimetry and individual behavior of inhabitants.

On 24 August 1956, the nuclear explosion with 27 kiloton total yield took place, which contaminated a territory to the east from the hypocenter and near Ust-Kamenogorsk city, Znamenka, Glubokoe, Tavriya, Gagarino and Shemonaikha settlements with radioactive fallout $[9,10]$. On 12 August 1953, the first thermonuclear explosion with 400 kiloton total yield took place, which contaminated the territory to the south from the hypocenter and near Sarzhal village with radioactive fallout [4, 11, 12]. On 7 August 1962, the nuclear explosion with 9.9 kiloton total yield took place, which contaminated a huge territory to the east from the hypocenter and near Kurchatov city, Akzhar, Begen, Semenovka, Grachi, Mayskoe and Buras villages with radioactive fallout [3, 13].

EPR dosimetry is one of the useful tools for such dose reconstruction [14, 15]. This method can determine the radiation doses retrospectively even more than 40 years after the exposure event. EPR measures the amount of the stable radicals created by radiation exposure in tooth enamel.

\section{Materials and Methods}

More than 200 teeth samples were collected from the population residing around SNTS. 105 teeth samples were extracted on the basis of medical indications from the adult residents of Dolon, Mostik, Bodene, Cheremushki, Kanonerka villages, located near the radioactive fallout trace formed as result of the most hazardous nuclear test of 1949 [16] and Semipalatinsk (Semey) city. 57 teeth samples were extracted from residents of Kurchatov City, Akzhar, Begen, Semenovka, Grachi, Mayskoe and Buras villages which are located from 70 to $150 \mathrm{~km}$ from SNTS [13]. In 2008 and 2009, 88 teeth samples were extracted according to medical reasons from adult residents of Znamenka, Glubokoe, Tavriya, Gagarino, Shemonaikha settlements and Ust-Kamenogorsk city [9, 10]. 6 teeth samples were collected from Sarzhal village and 8 teeth were collected as controls from the population of Kokpekty village (400 km east of the test site), which was not subjected to any radioactive contamination.

All samples were treated by hard alloy dental drills and diamond saws by separating the enamel from the dentine after the cutting of each tooth sample to buccal and lingual parts $[15,17]$. Dentins were removed carefully in order to prevent the sample from heating which can induce an additional EPR signal and significantly change shape of the signal [18-20]. Tooth enamel was crushed by cutting pliers to chips $0.5-1.5 \mathrm{~mm}$ in diameter.

The measurements were carried out in the X-band on the EPR spectrometer JEOL JES-FA100 at stabilized room temperature of $21^{\circ} \mathrm{C}$. The spectrometer was equipped with a high Q-factor cylindrical TE 011 cavity model ES-UCX2. The spectrum recording parameters were the same as previously published [21-24]. Specially designed computer software was used for spectra processing and dose estimation [25-27].

\section{Results and Discussion}

The doses for the residents of Kurchatov City, Akzhar, Begen, Semenovka, Grachi, Buras villages (table 1) were included in this report from the published data [13]. 
Table 1. Results of dose determination for population as a result of surface nuclear tests in 7, August 1962 in the Semipalatinsk Nuclear Test Site. Dose values and its errors are reflected in mGy.

\begin{tabular}{|c|c|c|c|c|c|}
\hline \multirow{2}{*}{ Settlements } & \multirow{2}{*}{$\begin{array}{l}\text { Number } \\
\text { of teeth }\end{array}$} & \multirow{2}{*}{$\begin{array}{c}\text { Archival } \\
\text { dose (mSv) } \\
\text { (Logachev) }\end{array}$} & \multicolumn{2}{|c|}{$\begin{array}{l}\text { EPR average excess dose with } \\
\text { enamel formation (mGy) }\end{array}$} & \multirow{2}{*}{$\begin{array}{c}\text { EPR } \\
\text { maximal } \\
\text { excess dose } \\
(\mathrm{mGy})\end{array}$} \\
\hline & & & Before 7.08.62 & After 7.08.62 & \\
\hline Akzhar & 8 & $5-10$ & $31 \pm 27$ & $-13 \pm 29$ & 202 \\
\hline Begen & 10 & $5-10$ & $82 \pm 30$ & - & 153 \\
\hline Buras & 4 & 10 & $101 \pm 34$ & $14 \pm 27$ & 187 \\
\hline Grachi & 5 & 10 & $-17 \pm 29$ & $52 \pm 26$ & 40 \\
\hline Kurchatov & 16 & 10 & $41 \pm 35$ & $1 \pm 30$ & 180 \\
\hline Mayskoe & 4 & $<5$ & $50 \pm 31$ & $70 \pm 27$ & 134 \\
\hline Semenovka & 10 & 10 & $60 \pm 29$ & - & 148 \\
\hline Kokpekty & 8 & $<0.1$ & $0.01 \pm 1.92$ & $0.01 \pm 1.92$ & 24 \\
\hline
\end{tabular}

For Kurchatov average excess dose before 1962 is $41 \pm 35 \mathrm{mGy}$ and after 1962 is $1 \pm 30 \mathrm{mGy}$. Low doses were found for the group with enamel formed after 1962, the end of atmospheric nuclear tests. The dose values for the group having enamel formed before 1962 are consistent with estimations based on the official registered data indicating high levels of the fallout in the period of 1949-1962. The experimentally determined dose was considered to consist of two contributions: dose from natural radiation background accumulated during a tooth enamel lifetime and dose obtained as a result of nuclear tests (excess dose). The last contribution is subject of the interest for present dose reconstruction. At first, the intensity of the RIS was converted into a dose absorbed by enamel $\mathrm{D}_{\text {en }}$ (expressed in mGy) calibrated using calibration by a ${ }^{60} \mathrm{Co} \gamma$-source. Second, excess dose in enamel was determined by subtraction of contribution of the natural background radiation during the enamel existence after its formation from the absorbed dose in enamel.

For the residents of Dolon absorbed doses were found to be in the range from $-24 \pm 37$ to $496 \pm 55 \mathrm{mGy}$. Negative doses were obtained for some values. It is natural that some of the values become negative according to their statistical distribution determined due to experimental errors. The negative doses probably are the result of the underestimation of uncertainty of the dose assessment. This is because the measurements were performed near the threshold of sensitivity of the EPR method.

For all the samples, excess doses were calculated by equation:

$$
\mathrm{D}_{\mathrm{ex}}=\mathrm{D}_{\mathrm{en}}-\mathrm{TA} * \mathrm{D}_{\mathrm{b}}
$$

Where: $\mathrm{D}_{\mathrm{en}}-$ dose calculated by automatic program, in $\mathrm{mGy}$

TA - teeth enamel age, years

$\mathrm{D}_{\mathrm{b}}$ - background dose, $0.8 \mathrm{mGy} /$ year $[28,29]$.

Uncertainty of dose determination $(E r)$ was determined based on formula used in the previous publication $[6,14,16]$.

The average excess dose for enamel formed before 1949 for Dolon is $153 \pm 54 \mathrm{mGy}$ (table 2), for enamel formed after 1949 the average dose is $25 \pm 11 \mathrm{mGy}$. For Mostik excess dose before 1949 is $19 \pm 15$ and after 1949 is $44 \pm 14$. For Bodene excess dose before 1949 is $74 \pm 40$ and after 1949 is $17 \pm 10$. For Cheremushki average excess dose before 1949 is $104 \pm 34$ and after 1949 is $4 \pm 27$. For Kanonerka average excess dose before 1949 is $48 \pm 29$ and after 1949 is $23 \pm 27$. For Semipalatinsk City average excess dose before 1949 is $145 \pm 68$ and after 1949 is $74 \pm 35$. The value of average dose for Semipalatinsk City is close to the average results of Dolon village $[5,12]$. One of the explanations is the person who worked in a place located close to SNTS and another explanation that they were born 
in the village that was affected by the fallout from Test Site. The bulk of the excess doses are near the sensitivity threshold of the method. For control samples, excess doses are from $-66 \pm 39$ up to $24 \pm 39 \mathrm{mGy}$, for Dolon from $-74 \pm 38$ up to $440 \pm 106 \mathrm{mGy}$, for Mostik from $-64 \pm 32$ up to $119 \pm 51$, for Bodene from $-50 \pm 38$ up to $356 \pm 58 \mathrm{mGy}$, for Semipalatinsk City from $0 \pm 46$ up to $268 \pm 79$ (table 2). The experimentally measured individual doses can be compared with the dose reconstruction data, which was demonstrated in previous publications $[7,8]$ and its amount was about 0.5 Gy for Dolon.

Table 2. Information about samples from vicinity to radioactive fallout traces as a result of surface nuclear tests in 29, August 1949 in the Semipalatinsk Nuclear Test Site.

\begin{tabular}{|c|c|c|c|c|}
\hline Settlement & $\begin{array}{c}\text { Number of } \\
\text { teeth } \\
\text { samples }\end{array}$ & $\begin{array}{c}\text { Enamel } \\
\text { formed } \\
\text { before 1949 }\end{array}$ & $\begin{array}{c}\text { ESR average excess dose } \\
\text { with enamel formation } \\
\text { before 1949 (mGy) }\end{array}$ & $\begin{array}{c}\text { ESR average } \\
\text { excess dose with } \\
\text { enamel formation } \\
\text { after 1949 (mGy) }\end{array}$ \\
\hline Dolon & 38 & 17 & $141 \pm 37$ & $25 \pm 11$ \\
\hline Mostik & 23 & 12 & $19 \pm 15$ & $44 \pm 14$ \\
\hline $\begin{array}{c}\text { Bodene } \\
\text { Cheremushki }\end{array}$ & 20 & 9 & $74 \pm 40$ & $17 \pm 10$ \\
\hline Semipalatinsk & 9 & 3 & $104 \pm 34$ & $74 \pm 35$ \\
\hline Kanonerka & 3 & 1 & $145 \pm 68$ & $23 \pm 27$ \\
\hline Total & 97 & 47 & $48 \pm 29$ & - \\
\hline
\end{tabular}

Table 3. Information about tooth samples from the settlements located close to radioactive fallout trace as a result of surface nuclear tests in 24, August 1956 in the Semipalatinsk Nuclear Test Site.

\begin{tabular}{|c|c|c|c|}
\hline Settlements & $\begin{array}{c}\text { Archival dose } \\
(\mathbf{m S v})\end{array}$ & $\begin{array}{c}\text { ESR average excess } \\
\text { dose (mGy) }\end{array}$ & $\begin{array}{c}\text { ESR maximal excess } \\
\text { dose (mGy) }\end{array}$ \\
\hline Znamenka & 25 & $41 \pm 46$ & 268 \\
\hline Glubokoe & $10-15$ & $36 \pm 31$ & 83 \\
\hline Tavriya & $10-15$ & $17 \pm 36$ & 54 \\
\hline Ust-Kamenogorsk & 80 & $20 \pm 25$ & 120 \\
\hline Gagarino & $10-15$ & $-24 \pm 33$ & 47 \\
\hline Shemonaikha & 0.1 & $17 \pm 37$ & 110 \\
\hline
\end{tabular}

For Tavriya and Gagarino villages all studied samples have been formed before the date of the nuclear test. For other settlements teeth samples were divided into two parts: before and after nuclear explosion. Low mean excess doses have been found for Gagarino residents, while the highest mean excess dose has been determined for Shemonaikha and Ust-Kamenogorsk residents (Table 3). Given the small number of tooth samples investigated, the deduced doses should not be seen as representative for the whole population in the selected villages. The maximum dose obtained for samples from Shemonaikha was not expected, due to its large distance from the radioactive trace, but may be due to radioactivity released by some of the uranium enterprises located there. The maximum dose obtained for Znamenka village $[9,10]$ can confirm that this village located close to the radioactive trace. The other settlements included in the study also have uranium enterprises, except for Tavriya and Gagarino, where agriculture is prevalent. Average excess doses in the latter two settlements are consistent with estimations based on the official registered data indicating high levels of fallout in the period of 1949-1962. 
Also data of absorbed doses from residents of Sarzhal village, which is located close to fallout trace after test in 12, August 1953. According to archival data [4] the dose was about $500 \mathrm{mSv}$ and this is much higher than reported in table 4. This can be due to evacuation of residents from Sarzhal village to Ayaguz settlements which is located $150 \mathrm{~km}$ from Sarzhal.

Table 4. Information about tooth samples from the settlements located close to radioactive fallout trace as a result of surface nuclear tests in 12, August 1953 in the Semipalatinsk Nuclear Test Site.

\begin{tabular}{|c|c|c|c|c|}
\hline Settlements & $\begin{array}{c}\text { Number of } \\
\text { teeth samples }\end{array}$ & $\begin{array}{c}\text { Archival dose (mSv) } \\
\text { (Logachev) }\end{array}$ & $\begin{array}{c}\text { ESR average } \\
\text { excess dose } \\
\text { (mGy) }\end{array}$ & $\begin{array}{c}\text { ESR maximal } \\
\text { excess dose } \\
\text { (mGy) }\end{array}$ \\
\hline Sarzhal & 6 & 500 & $79 \pm 31$ & $138.2 \pm 35$ \\
\hline
\end{tabular}

\section{Conclusion}

Higher average excess doses were determined in Dolon and Semipalatinsk city for residents whose tooth enamel was formed before 1949. Results of dose estimation from Dolon samples are in agreement with the fact that this village is located closer to the axis of the radioactive trace. A result from Semipalatinsk needs special investigation.

Compared to samples from the distant Kokpekty village which was chosen as controls, higher average excess doses have been obtained for Znamenka, Ust-Kamenogorsk city and Shemonaikha. This is in agreement with the fact that Znamenka village and Ust-Kamenogorsk city are located close to the axis of the radioactive trace, but Shemonaikha is located on the distance about $70 \mathrm{~km}$ from it. It is necessary to note, that the investigated area is well known for its active uranium processing plant. This may explain that higher values have also been found for samples from Shemonaikha, which is located about $70 \mathrm{~km}$ from the center line of the radioactive trace. At Tavriya and Gagarino no uranium enterprises exist and, accordingly, the measured doses are consistent with independent estimates of external doses from the fallout that can be found in the literature.

\section{Acknowledgements}

This work partly was supported by Grant-in-Aid for Young Scientists (B) from Japan Society for the Promotion of Science \#21710060.) And by the Grant of Ministry of Education and Science of Kazakhstan (5284/GF4 agreement No 47).

\section{References}

1. O.I. Artemev, M.A. Akhmetov, V.N. Larin, L.D. Ptitskaya, K.S. Zhumadilov, G.P. Silkina, S.B. Subbotin, NATO advanced science institute series, sub-series: Disarmament technologies 31, 16 (2000)

2. A.I. Ivannikov, Zh. Zhumadilov, B.I. Gusev, Ch. Miyazawa, L. Jiao, V.G. Skvortsov, V.F. Stepanenko, J. Takada and M. Hoshi, Health Phys. 83, 13 (2002)

3. K. Gordeev, S. Shinkarev, L. Ilyin, A. Bouville, M. Hoshi, N. Luckyanov, S.L. Simon, J. Radiat. Res. 47, 7 (2006)

4. V.A. Logachev, M., IzdAT, 470 (2008)

5. K. Zhumadilov, A. Ivannikov, K.N. Apsalikov, Zh. Zhumadilov, Sh. Toyoda, E. Tieliewuhan, S. Endo, K. Tanaka, C. Miyazawa, T. Okamoto, M. Hoshi, J. Radiat. Res. 47, 6 (2006) 
6. A. Ivannikov, K. Zhumadilov, E. Tieliewuhan, L. Jiao, K.N. Apsalikov, G. Berekenova, Zh. Zhumadilov, Sh. Toyoda, C. Miyazawa, V. Skvortsov, V. Stepanenko, S. Endo, K. Tanaka, M. Hoshi, J. Radiat. Res. 47, 7 (2006)

7. V.F. Stepanenko, M. Hoshi, Yu.V. Dubasov, A. Sakaguchi, M. Yamamoto, M. Orlov, I.K. Bailiff, A.I. Ivannikov, V.G. Skvortsov, I.G. Kryukova, K.S. Zhumadilov, K.N. Apsalikov, B.I. Gusev, J. Radiat. Res. 47, 9 (2006)

8. V.F. Stepanenko, M. Hoshi, A.I. Ivannikov, I.K. Bailiff, K. Zhumadilov, V.G. Skvortsov, R. Argembaeva, A.F. Tsyb, Radiat. Meas. 42, 7 (2007)

9. K. Zhumadilov, A. Ivannikov, Z. Zhumadilov, V. Stepanenko, K. Apsalikov, M. Rodzi, A. Zhumadilova, S. Toyoda, S. Endo, K. Tanaka, T. Okamoto, M. Hoshi, Radiat. Environ. Biophys. 48, 6 (2009)

10. K. Zhumadilov, A. Ivannikov, Z. Zhumadilov, V. Stepanenko, Sh. Abralina, L. Sadvokasova, A. Zhumadilova, S. Toyoda, S. Endo, T. Okamoto, M. Hoshi, Radiat. Meas. 46, 4 (2011)

11. S. Sholom, M. Desrosiers, A. Bouville, N. Luckyanov, V. Chumak, S.L. Simon, Radiat. Meas. 42, 4 (2007)

12. K. Zhumadilov, A. Ivannikov, V. Stepanenko, S. Toyoda, Z. Zhumadilov, M. Hoshi, J. Radiat. Res. 54, 4 (2013)

13. K. Zhumadilov, A. Ivannikov, V. Stepanenko, S. Toyoda, V. Skvortsov, M. Hoshi, Radiat. Prot. Dosim. 172, 4 (2016)

14. IAEA-TECDOC-1331, Vienna (2002). http://www-pub.iaea.org/MTCD/publications/PDF/te_1331_web.pdf

15. P. Fattibene, A. Wieser, E. Adolfsson, L.A. Benevides, M. Brai, F. Callens, V. Chumak, B. Ciesielski, S. Della Monaca, K. Emerich, H. Gustafsson, Y. Hirai, M. Hoshi, A. Israelsson, A. Ivannikov, D. Ivanov, J. Kaminska, Wu Ke, E. Lund, M. Marrale, L. Martens, C. Miyazawa, N. Nakamura, W. Panzer, S. Pivovarov, R.A. Reyes, M. Rodzi, A.A. Romanyukha, A. Rukhin, S. Sholom, V. Skvortsov, V. Stepanenko, M.A. Tarpan, H. Thierens, S. Toyoda, F. Trompier, E. Verdi, K. Zhumadilov, Radiat. Meas. 46, 6 (2011)

16. K. Zhumadilov, A. Ivannikov, K. Apsalikov, Zh. Zhumadilov, V. Stepanenko, V. Skvortsov, G. Berekenova, S. Toyoda, S. Endo, K. Tanaka, C. Miyazawa, M. Hoshi, Radiat. Meas. 42, 4 (2007)

17. A. Wieser, E. Vasilenko, P. Fattibene, S. Bayankin, N. El-Faramawy, D. Ivanov, P. Jacob, V. Knyazev, S. Onori, M.C. Pressello, A. Romanyukha, M. Smetanin, A. Ulanovsky, Radiat. Environ. Biophys. 44, 9 (2006)

18. A. Romanyukha, V. Nagy, O. Sleptchonok, M.F. Desrosiers, J.J. Jiang, A. Heiss, Health Phys. 80, 3 (2001)

19. A.I. Ivannikov, D. Sanin, M. Nalapko, V.G. Skvortsov, V.F. Stepanenko, A.F. Tsyb, F. Trompier, K. Zhumadilov, M. Hoshi, Health Phys. 98, 6 (2010)

20. A.I. Ivannikov, V.G. Skvortsov, V.F. Stepanenko, K.Sh. Zhumadilov, Radiat. Prot. Dosim. 159, 4 (2014)

21. K.S. Zhumadilov, A.I. Ivannikov, V.G. Skvortsov, Zh. Zhumadilov, S. Endo, K. Tanaka, M. Hoshi, J. Radiat. Res. 46, 7 (2005)

22. K. Zhumadilov, V. Stepanenko, A. Ivannikov, Z. Zhumadilov, S. Toyoda, K. Tanaka, S. Endo, M. Hoshi, Radiat. Environ. Biophys. 47, 4 (2008)

23. K. Tanaka, S. Endo, A. Ivannikov, S. Toyoda, E. Tieliewuhan, K. Zhumadilov, C. Miyazawa, S. Suga, K. Kitagawa, M. Hoshi, J. Radiat. Res. 46, 4 (2006) 
24. S. Toyoda, A. Kondo, K. Zhumadilov, M. Hoshi, C. Miyazawa, A. Ivannikov, Radiat. Meas. 46, 4 (2011)

25. A.I. Ivannikov, V.G. Skvortsov, V.F. Stepanenko, D.D. Tikunov, A.A. Romanyukha, A. Wieser, Radiat. Prot. Dosim. 71, 5 (1997)

26. V.G. Skvortsov, A.I. Ivannikov, V.F. Stepanenko, A.F. Tsyb, L.H. Khamidova, A.E. Kondrashov, D.D. Tikunov, Appl. Radiat. Isot. 52, 7 (2000)

27. E. Tielewuhan, A. Ivannikov, K. Zhumadilov, M. Nalapko, D. Tikunov, V. Skvortsov, V. Stepanenko, Sh. Toyoda, K. Tanaka, S. Endo, M. Hoshi, Radiat. Meas. 41, 7 (2006)

28. M. Hoshi, S. Toyoda, A. Ivannikov, K. Zhumadilov, A. Fukumura, K. Apsalikov, Z.S. Zhumadilov, S. Bayankin, V. Chumak, B. Ciesielski, V. De Coste, S. Endo, P. Fattibene, D. Ivanov, C.A. Mitchell, S. Onori, M. Penkowski, S.P. Pivovarov, A. Romanyukha, A.B. Rukhin, K. Schultka, T.A. Seredavina, S. Sholom, V. Skvortsov, V. Stepanenko, K. Tanaka, F. Trompier, A. Wieser, G. Wolakiewicz, Radiat. Meas. 42, 9 (2007)

29. A. Ivannikov, S. Toyoda, M. Hoshi, K. Zhumadilov, A. Fukumura, K. Apsalikov, Z.S. Zhumadilov, S. Bayankin, V. Chumak, B. Ciesielski, V. De Coste, S. Endo, P. Fattibene, D. Ivanov, C.A. Mitchell, M Nalapko, S. Onori, M. Penkowski, S.P. Pivovarov, A. Romanyukha, A.B. Rukhin, D. Sanin, K. Schultka, T. Seredavina, S. Sholom, V. Skvortsov, V. Stepanenko, K. Tanaka, F. Trompier, A. Wieser, G. Wolakiewicz, Radiat. Meas. 42, 5 (2007) 